\title{
A Poverty of Rights: Six Ways to Fix the MDGs
}

\author{
Malcolm Langford
}

\begin{abstract}
The reactions of the human rights community to the MDGs have been diverse. The goals have given a clear, communicable and quantitative focus to development but they arguably distract attention from important issues and are structurally flawed. In looking backwards, we need to consider whether the human rights gaps in the MDGs architecture are partly responsible for the mixed success of the enterprise and whether the MDGs are also being used to avoid human rights commitments. This reflection is used to look forwards to 2015 and it is argued that, even if we accept the target-based approach, human rights can make six key contributions, namely: (1) increasing participation in target selection; (2) ensuring targets better reflect human rights; (3) aiming for equality not just average improvements; (4) adjusting the targets for resource availability; (5) locating economic trade-offs within a human rights-based normative framework; and (6) improving the accountability infrastructure.
\end{abstract}

\section{Introduction}

The Millennium Development Goals (MDGs) were greeted with disbelief and praise by those focused on human rights. It was disbelief from commentators who saw the MDGs as a betrayal of more demanding and/or nuanced international human rights commitments; the 'Major Distracting Gimmicks' as one women's rights advocate labelled them (Saith 2006). It was praise from those who saw them as a bridge between the human rights and development agendas (Jahan 2003).

Between these two reactions, one can find many shades. Some like Alston (2005) and UNDP (2008) straddle the contrarian positions, arguing that the MDGs are an adequate reflection of socioeconomic rights and the real challenge is to integrate human rights into development practice. The UN Office of the High Commissioner for Human Rights (UN OHCHR 2008) has been more critical, urging States to better align the targets at the country level with human rights and then ensure integration in practice. For others, the MDGs seemed to have passed by unnoticed; possibly from ignorance, possibly from the fact that MDGs were seen as contributing little to strategies on human rights and social justice.
The end result has been a mixed and fragmented engagement by human rights non-governmental organisations (NGOs), social movements, lawyers and UN human rights bodies. One empirical survey of attitudes found that many Northern NGOs embraced the MDGs, while those in South preferred rights-based standards (Nelson 2007). From the perspective of pragmatism, it is tempting to fudge some sort of middle position on the human rights and MDGs debate. But it carries dangers. For instance, Alston (2005) seeks to largely defend the MDG design from a human rights perspective but he is simultaneously puzzled as to why human rights are almost entirely absent in MDG-related policy guidance, strategies and reporting. He does not adequately stop to ask whether the problem might be the original design. We thus need to go deeper and ask two questions. First, are the 'human rights' gaps in the MDGs architecture partly responsible for the mixed success in reaching the Targets? Second, would a critical reading from a human rights perspective alert us to the potential that the Targets could be used to avoid human rights commitments and perpetuate violations? The latter scenario has unfortunately been all too common in the history of international development policy. 
This is not to dismiss the sunny side of the MDGs agenda. The Goals have given a clear, communicable and quantitative focus to international and sometimes national development priorities. One can discern shifts among donors, UN agencies and the World Bank in the allocation of aid that is attributable to the Goals. Some national governments from Kenya (Government of Kenya 2005) to Indonesia (Government of Indonesia 2007), claim that the MDGs have influenced their domestic spending priorities, while political discourses and campaigns on poverty have been shaped by MDGs language. MDG 5 has seemingly inspired international campaigns on maternal mortality by the former UN Special Rapporteur on the Right to Health and now Amnesty International. Moreover, there has been some attentiveness to the MDG critiques and a target on reproductive rights was included in 2007. However, Sakiko Fukuda-Parr (2008: 1) points out that while Poverty Reduction Strategies have increased their focus on social sector investments (MDGs 2-6), other areas such as 'decent work, hunger and nutrition, the environment and access to technology tend to be neglected'.

As many development critics have discussed elsewhere, determining the impact of the MDGs in isolation from other causal factors is fraught with difficulty. Progress in some Targets such as income poverty is partly attributable to the preMDG efforts of China, India and Vietnam (Smith 2007). Achievements on HIV/AIDS (MDG 6) have largely occurred outside the MDG framework - for example, a slew of more precise targets on HIV were adopted in 2001 by the General Assembly but these were never integrated in the MDG monitoring system. However, less discussed in terms of impact are the negative human rights 'externalities' that have resulted from some of the MDG Targets. These are often not picked up in the monitoring. And how does one determine the human rights counter-factual - i.e. would a more human rightsfriendly MDG design have done a better job?

In the emerging discussions on post-2015, it is interesting to observe the increased weight given to human rights. Calls are being made to repoliticise the MDGs, base them firmly on human rights values, return to the original rights-focused vision of the Millennium Declaration and even to frame part of the overarching development discourse in terms of rights, for example global social rights or global social citizenship. These calls are to be welcomed; indeed, one is almost tempted to hope that 2015 may be the moment when economic and social rights will come in from the global cold.

In this article, I want to look more at the practical consequences of bringing in human rights; both in process and substance and by looking critically backwards to 2000 and forward to 2015. The first section or 'fix' in this article will thus focus on the process for formulating new development mandates from a human rights perspective. It will examine what went wrong in 2001 and what could go right for 2015. The next five 'fixes' concern how the 2000/2001 MDG framework could have been better shaped by human rights, from both principled and instrumental perspectives. These latter points assume that we might continue with a targetbased approach post-2015. While the targetbased approach is under discussion itself, I use this framework to demonstrate the possible practical and design consequences of a human rights approach. In other words, if we accept the MDG-style targeting approach, where could human rights take us?

\section{Stopping at the participation sign}

Before we begin to dream up new post-2015 roads, we need to stop at the participation sign. If we are to take human rights seriously, then the design of the MDGs cannot be simply left to a few international agencies and a group of invisible experts in New York (or Brussels) as it was in 2001. This is not to disparage the group completely. They faced the difficult task of trying to operationalise the Millennium Declaration and, to a certain degree, they were inventive in trying to fold some of the broader aspects of the Declaration, such as environment, into the Goals and push the envelope with some additional Indicators, even if they lacked Targets. At the same time, a neoliberal agenda appeared to have set in during this process, and there are many alarming omissions from the Declaration:

Affordable water. The target for affordable water in the Declaration was dropped from the MDGs. Perhaps the target was deemed 'unmeasurable' but indexes of water affordability are available. Or was affordability dropped in order to allow space 
for privatisation of water utilities - a strategy very much in vogue at the time?

- Orphans from HIV/AIDS. The Declaration target of providing 'special assistance to children orphaned by HIV/AIDS', one of the world's most vulnerable groups, was likewise completely and inexplicably omitted from the MDGs.

- Equitable trade. The Declaration called for a trading system that was 'open, equitable, rulebased, predictable and non-discriminatory', but one is startled to find in MDG Target 8A that the crucial word 'equitable' was deleted.

- Gender equality and empowerment of women. The Declaration contained a general target in paragraph 20 of promoting 'gender equality and the empowerment of women as effective ways to combat poverty, hunger and disease and to stimulate development that is truly sustainable'. Instead of fashioning some targets, perhaps along the lines of the Beijing Declaration, this broad Declaration target was whittled down to being the title of Goal 3 with a quantitative Target for equality in primary and secondary education. This is to be contrasted with other general targets in this paragraph where there some efforts to fashion them as (at least) qualitative Targets in Goal 8. After an initial critique, UNIFEM (2004) embarked on the task on trying to show how gender can be mainstreamed in each Target but one still wonders whether some clear Targets might have helped focus more attention on the gender gap in development: from land ownership to political representation. This omission of targets is startling on the face of the 2001 MDG list, where an additional four Indicators are added but there are no accompanying Targets.

There was also no attempt to include other key elements of the Declaration, particularly human rights, as Goals or Targets, as was done with environment. Yet, the Declaration specifically speaks of the connections between human rights and development. This orphaning of specific aspects of the Declaration is possibly the reason for the UN General Assembly's reluctance, contrary to common belief, to embrace the 2001 Goals, Targets and Indicator list. It was only in October 2005 that the General Assembly made reference to it; all earlier resolutions had focused on calling for implementation and monitoring of all the Goals and measures in the broader Millennium Declaration framework.
But not all the blame can be laid at the feet of the 2001 technocratic takeover. Some of the flaws lie in the selection of the targets in the Millennium Declaration, as will be discussed below. Broader participation and greater attention to human rights could have improved the precision and focus of the targets.

So what kind of process can take us to 2015? How can grassroots groups, Southern-based NGOs, human rights advocates, under-capacitated ministries in developing countries be properly involved this time around?

There will be great temptation to create some sort of Bruntland-style Commission of high level politicians and experts to come up with a new development vision. But the recent experience with the Commission on the Legal Empowerment of the Poor (CLEP) (led by Hernando de Soto), shows its limitations. CLEP was modelled on the Bruntland Commission but came under vociferous attack for its non-representativity and its focus on the magic bullet of formalisation, a policy which had undermined land and livelihood rights of the poor in many contexts. The outcry led to the addition of regional consultations and creation of advisory boards (see discussion of issues and process in Langford 2007). This adjustment brought in other voices but the rushed and bifurcated process led to serious splits within the Commission and a report that was balanced but fundamentally contradictory with something for everybody, as the Economist (2008) gleefully pointed out.

The key lesson from the CLEP experience is that one needs time and attention to ensure some sort of genuine bottom-up participatory process. While any final decision needs to be made within the current confines of international law, ideas for high level commissions need to be put on the backburner until a more participatory mechanism can be commenced; where those who are meant to be the 'beneficiaries' of development have a direct say in how it is conceived.

\section{Put the Targets in front of a human rights mirror}

Creating a list of targets large enough to address poverty's dimensions but short enough to avoid unwieldiness is more art than science. Nonetheless, the current list of targets still begs too many questions, despite its seeming 
artfulness. The MDGs appear more driven by the availability of data than a concrete vision of what the global community wanted to achieve and measure. Of course it is possible to demonstrate linkages between various socioeconomic rights and existing MDG Targets, and some in the human rights community have drawn pretty tables to this effect. But it largely misses the point of a human rights approach. The key questions are whether the rights were sufficiently covered, and more importantly, whether the substance of the target actually reflects the legal standard.

If we just confine ourselves to socioeconomic rights, we would see a number of Goals, Targets and Indicators in both the 2000 and 2001 lists that are in desperate need of adjustment:

- Goal 1. First, where is the right to social security under the first Goal? Imagine if a target for building basic social protection packages had been set in 2000. The numbers of those slipping into poverty through the current global economic crises could have been palpably less. According to the International Labour Organization (ILO), the cost to Senegal, India and Vietnam of providing child grants to all households with school-age children is around 1 per cent of GDP, rising to 2 per cent in Tanzania (Gassmann and Behrendt 2006; Mizunoya et al. 2006). These estimates are close to actual costs in other developing countries which have taken the plunge. There is now a rising movement to try and insert a social protection target in 2010 but a mere glance at international human rights standards from 1948 to 2000 would have revealed a consistent and strong emphasis on this right. One might have also thought about access to land rights and inequality in distribution given the role of land for most of the rural poor in creating and sustaining livelihoods necessary to reach Goal 1.

- Goal 2. The target of universal access of primary education resonates with State obligations in the Convention on the Rights of the Child and the International Covenant on Economic, Social and Cultural Rights. However, both of these human rights treaties mandate that it must also be free, compulsory and of a certain quality. Article 14 of the International Covenant on Economic, Social and Cultural Rights (ICESCR) additionally provides that States which are not providing free primary education to all must prioritise the achievement of that commitment within a reasonable number of years (and certainly not 15 or 25!). In the MDG context, free primary education is often promoted as a good strategy - Kenya's policy shift in 2003 being promoted as the poster child. But it has been relegated to precisely that - a strategy not a right. The absence of a target for free education was evident in a recent review of a sample of MDG country reports - it was difficult to find countries measuring the affordability, quality or compulsory nature of education, which can be very important for girls' education (UN OHCHR, UNICEF and NCHR 2008) - although some countries like Malawi had recognised the importance of quality education for ensuring student attendance.

- Goal 5 is particularly impressive with its focus on a large-scale reduction of maternal mortality (75 per cent). Its inclusion of conduct-based index of birth attendants is welcome, given the problems of the maternal mortality indicators. But where are the more sophisticated and human rights-friendly targets from the 1997 UN Guidelines for Monitoring the Availability and Use of Obstetric Services? Their inclusion could have prompted countries like India to go beyond policy promises on Emergency Obstetric Services and actually measure them.

- Goal 7 is the most embarrassing of the national targets. Beyond the vacuous environmental targets, one meets the tortoiselike target of improving the lives of a mere 9 per cent of 'slum dwellers' by 2020, i.e 100 million of 1.6 billion slum dwellers. What the target designers further failed to grasp is that the most immediate issues for many 'slum dwellers' is security of tenure, access to services and participatory planning. A cursory reading of housing rights standards, jurisprudence and practice demonstrates that these elements should be addressed first. In States where resources are few and corruption is high, these basic conditions are crucial for the poor to be able to develop their own housing solutions. Instead, the narrow focus on improving just a few lives often fuels white elephant-style slum upgrading projects (COHRE 2006). Moreover, the framing of this target has arguably helped provide justification for human rights violations (see below).

- Goal 8 looks good on first blush perspective but the developed countries have cleverly 
wriggled out of the types of quantitative targets that were set for developing countries. The qualitative targets are matched only with a detailed list of indicators from debt relief to development aid and trade that beg the creation of real benchmarks. This absence of quantitative targets is reflected in many donor reports, which tend to list development aid projects and programmes without a detailed assessment of how they are systematically addressing the range of issues raised in MDG 8. During 2001-08 some achievements have been made in setting such targets (e.g. on aid but not trade), but even these are far from being met and are more restrictive in practice than imagined.

- To this could be added targets on inequality where are persons with disabilities, migrants and ethnic minorities? And where are civil and political rights, trumpeted by the Millennium Declaration and arguably crucial to long-term sustainable development? Mongolia's Goal 9 on democratic governance and human rights with time-bound targets deserves investigation.

The above critique and series of proposals is not meant to advocate an over-elasticated laundry list of goals and targets, although it is notable that Ecuador developed a list of 100 indicators to measure MDG performance. Rather it is about paying attention to whether human rights law and principles provide critical and substantive perspectives in the way in which the MDG Goals, Targets and Indicators are framed. With a little imagination, I suspect we could have ended up with ten MDGs and a few more targets.

\section{From cherry-picking to equality}

The Targets are problematic in being largely unfocused on the poorest of the poor or reducing inequality. These are both key requirements within human rights and the MDG approach can make it tempting for States to cherry-pick the relatively well-off among the poor and ignore long-suffering and excluded minorities. This is further accented by the fact that many marginalised groups are not recognised in the MDGs. The 2001 MDG framework did quietly add some Indicators on the severity and depth of income poverty but there were no quantitative Targets fashioned for them.

Some countries have sought to overcome the equality problem during national tailoring and contextualisation. The MDG-plus framework in Thailand adds specific Targets for disadvantaged regions in the country. In Kenya, each region must now improve water and sanitation access by 10 per cent a year. These equality-based Targets conform with the idea proposed by Dan Seymour of UNICEF of making MDG progress conditional on meeting their Targets in all regions of a country. One could do the same with all ethnic groups, genders, etc. A second approach to such equality targeting is to provide targets for income poverty indicators such as severity and depth; something Bangladesh has done (Anderson and McKay 2008).

One additional question is whether the MDG Target framework meets the requirement that States need to immediately reach a minimum essential level of the rights unless they can demonstrably justify that resources are not available (UN GESCR 1991). For example, this could require that a very poor State devotes its limited resources to ensuring that all the hungry have improved access to food than simply halving the number of those officially classified as hungry. Should the other 50 per cent be expected to wait 15-30 years before they are addressed? In some cases, it may be highly impractical or irrelevant in attempting a modest increase in access for all. However, simple and new interventions could assist. For example, Gassmann and Behrendt (2006) econometrically model a child benefit for Tanzania and Senegal that is set at a level (35 per cent of the national food poverty line) that is not intended to take all children above the poverty line but rather move all children towards or over that line. Do we thus need to develop some targets that can be met immediately for all (particularly those affecting survival), even if it is does not fit perfectly with long-term development strategy?

\section{From MDG-plus to MDG-adjust}

The MDG-plus approach of a number of countries has begun to garner favour in the development community. This is not surprising. The pitfalls of global target-setting were revealed immediately when some countries began boasting of success within a few years of the Declaration. This is particularly the case in middle-income countries which already had more ambitious targets or possessed the capacity to quickly halve or address smaller gaps. Officials at the Department of Water and Environment 
Affairs in South Africa recently commented that the water target is irrelevant given South Africa's earlier national commitments but that has not stopped the Government of South Africa trumpeting its success in reaching it so quickly.

Some countries and regions have taken a constructive approach to this problem and created MDG-plus Targets. The Latin American/ Caribbean region amended Target 2A to include secondary education with 75 per cent of children to be accorded access by 2010, while a number of Asian countries added higher or additional targets.

This MDG-plus agenda is now centre-stage in post-2015 thinking as a way of addressing the resource imbalances between States. However, is this idea simply a band-aid to cover a flawed model? Is it the best way of dealing with a situation where Kenya is expected to halve projected income poverty of 56 per cent and Vietnam 6 per cent in the same time period? How does one have Somalia and EU member Bulgaria in the same MDG mix? There are also calls to include all States, including from the West, next time around. MDG-plus thus seems rather ad hoc without any global or normative underpinnings.

If we turn to human rights, we can find a more nuanced approach although it is only beginning to be quantified. In treaties on economic, social and cultural rights, States are only expected to progressively realise the rights within their maximum available resources. Retrogression is severely frowned upon and States are expected to set reasonable benchmarks that should be achieved over time with a reasonable set of policies. Thus, the human rights architecture allows for state particularity but has one global standard for all. It does not let middle- or high-income countries off the hook and allows some latitude to poorer states.

One obvious way to compensate for different resource levels is to adjust targets for GDP, although this ignores aid and borrowing options that may increase with lower resources. Thus we might expect greater quantitative progress in proportionately reducing gaps every five years from Vietnam compared to Kenya. A second approach would be regional targets, which would be natural considering neighbourly homogeneity and competition in much of the world. Latin American countries acknowledged as such in setting MDG-plus targets for their region. A combination of this with GDP adjustment could also work. Such approaches could be complemented by the production possibility function for economic and social rights proposed by Fukuda-Parr et al. (2008) or country-based econometric methods for determining available resources (Anderson 2008). Of course such approaches should not distract attention from countries which require greater assistance in reducing large poverty gaps but they would at least keep in check middle and higher income countries.

When it comes to income poverty, a way must also be found to bring existing national poverty lines into the method for calculating the currently flawed international poverty line (Pogge 2005). For example, in Senegal the \$1-a-day measurement is substantially below the national poverty line, while it is the reverse in Tanzania (Gassmann and Behrendt 2006). In August 2008, the World Bank further confirmed these suspicions around the $\$ 1$-a-day measurement by releasing new poverty figures based on 2005 (instead of 1993) cost-of-living data which showed that a further 400 million people lived below an adjusted poverty measure of $\$ 1.25 /$ day. In Anderson and McKay's (2008) review of a sample of MDG reports, they found many countries measuring with national poverty lines, as opposed to the international poverty line.

\section{Trade-offs with rights}

The divorce of the MDGs from the Millennium Declaration has arguably led to a value-free policy space for the MDGs. It seems that anything goes in the quest to meet the MDGs. If massive human rights violations are the method, no one is the wiser as the figures show 'progress'. Take, for example, Target 7D where Vietnam reports slum clearance as part of their efforts in achieving the MDGs (Government of Vietnam 2005: 12). This is pronounced despite countless international standards inveighing against forced evictions (e.g. see UN Commission on Human Rights 1993).

Marie Huchzermeyer (2008) argues that a provincial slum clearance law in South Africa and moves to replicate it country-wide are based on a 'fundamentally flawed' interpretation by governments of MDG Target 7D and its accompanying slogan of 'Cities without Slums'. The sloppiness of the MDG target formulation has allowed states to use it as a pretext for 
violations of the housing rights of those who were intended to benefit from the Target.

Likewise, the MDGs have coincided with renewed interest in dams and a continuing focus on promoting large-scale commercial agriculture, although the World Bank is now sending out markedly contradictory signs on the latter. Such projects are regularly justified on the basis of addressing income poverty or providing clean energy and water resources, arguments that resonate with MDGs 1 and 7. However, development-based displacement continues apace (UN-Habitat 2007) and the MDGs risk being added as another 'public interest' criterion to justify gross violations of human rights. This is not to rule out relocation per se but most States do not have proper mechanisms in place to ensure individuals and communities are only evicted in accordance with human rights standards, i.e. there is substantive justification, due process and remedies.

Therefore, human rights need to be integrated into the MDG policy process. Red lines need to be drawn under what policies are permissible and under what normative framework trade-offs and choice-making will occur (Seymour and Pincus 2008). The principle of do no harm needs real teeth and must be foregrounded in the development package. The policy choice spectrum also needs to be proactively influenced by human rights. Some policy options are more likely to both fulfil development goals and tick off human rights objectives. Thus, future MDGs need to better encourage economic trade-offs which favour human rights. For example, if the research shows that smaller farmers are more, or as, efficient as larger farmers (Brink et al. 2006), why has largescale agriculture been pushed so hard? Likewise, space needs to be opened for different ways of economic development, particularly for indigenous peoples. There needs to be an emphasis on more bottom-up participation in deciding trade-offs, as has been very strongly recognised in the 2007 UN General Assembly Declaration on the Rights of Indigenous Peoples.

\section{From words to enforcement}

For a bunch of words with a simple monitoring system, the MDGs have had considerable success. Not radical but enough to influence global development discourse and the practice of some countries. Even still, the MDGs often seem to be a game of Forrest Gump's box of chocolates. Donors and governments pick and choose according to their own tastes despite the attempts at harmonisation à la Paris Declaration. MDG targets on sanitation, maternal mortality and slums are virtually invisible in many donor platforms let alone national policy.

Other forms of accountability are needed to complement the political rewards of MDG attainment. In Targeting Development, Black and White (2004: 17), acknowledge that a major weakness of the MDGs is the lack of rights-based accountability even though it has a rights-based flavour in setting a political form of accountability. In relation to the international actors they concede:

What is missing from discussion of targets for international development agencies is any theory of accountability. For real accountability, at the very least there needs to be more transparency as to who is responsible for what, and more ownership of goals by those expected to meet them. In this sense, scale is also important. Individuals and agencies need to be held accountable for targets that are realistic and achievable at the level at which they are working.

One approach is to look to the international human rights system with its engine of periodic reviews, complaint systems and expert mandates. It could play a larger role in development policy but is limited by design and suffers from some of the same weaknesses as the MDG monitoring system (see a general discussion in Alston 2005).

We thus need to be more imaginative and there follows a few suggestions:

- First, articulate specific development targets that require States to ensure that domestic accountability systems are in place. One could draw from the UN Committee on Economic, Social and Cultural Rights (CESCR) General Comment No. 9 on domestic provision of enforceable remedies. Judicial enforcement of socioeconomic rights has been particularly important in Latin American and South Asian countries and increasingly elsewhere (Langford 2008). 
- A second and similar road to take is to ensure that domestic space for political mobilisation and participation around poverty issues is encouraged and even targeted. The experience of Porto Alegre demonstrated that direct participation in discretionary budget allocations led to a remarkable and speedy closure of large gaps in access to basic services such as water and sanitation.

- Third, can we imagine a stronger international monitoring system? Can 2015 be a date to bring together development and human rights systems and create something more powerful? Does 2015 present a window of opportunity for some sort of big bang reform that cements global social citizenship at the core of international processes? And the creation of a stronger and broader human rights monitoring and enforcement system?

- And lastly, can one introduce some carrots? The EU accession process has been remarkably successful in spurring on domestic reform. Could improvement on domestic targets be rewarded with automatic progress on MDG 8 Targets (aid, trade, debt relief and, critically, labour mobility) in the future?

\section{Conclusion}

Starting to dream up a post-2015 approach to international development obviously carries dangers as it could distract those genuinely seeking to reach the 2015 Goals in an appropriate

\section{References}

Alston, Philip (2005) 'Ships Passing in the Night: The Current State of the Human Rights and Development Debate Seen Through the Lens of the Millennium Development Goals', Human Rights Quarterly 27.3: 755-829

Anderson, Edward (2008) Using Quantitative Methods to Monitor Government Obligations in Terms of the Rights to Health and Education, New York: Center for Economic and Social Rights Anderson, Edward and McKay, Andy (2008) Human Rights, the MDG Income Poverty Target and Economic Growth, Background Paper for UN OHCHR Africa and Asia Regional MDGs and Human Rights Dialogues for Action, Geneva: UN Office of the United Nations High Commissioner for Human Rights

Black, R. and White, H. (2004) Targeting Development: Critical Perspectives on the Millennium Development, London: Routledge manner. At the same time, it provides a useful forum to unpick some of the key faultlines in the MDGs and start to address the key weaknesses now rather than later. As the Office of the United Nations High Commissioner for Human Rights (UN OHCHR 2008), there is already much that can be done to align current targets at the national level with human rights and possibly some targets such as inequality, climate change and social protection could be added in 2010 .

But a full-scale integration of human rights into international development policy is an idea whose time has not yet come and is still not desired in some quarters. The point of this article, however, was to show that a human rights approach not only provides the poetry for new development visions or the complication of introducing civil and political rights, but that it also provides a framework for operationalising development in ways that have not yet been properly explored. Post-2015 provides a new opportunity for human rights to be taken seriously in international development. We need to be begin with a commitment to participatory process and attention to contributions that international and national human rights jurisprudence and practice can bring to the table, whether in the selection and framing of targets, the setting of state obligations or the creation of accountability frameworks that can ensure development, is not only achieved but sustained.

Brink, R.; Thomas, G.; Binswanger, H.; Bruce, J. and Byamugisha, F. (2006) Consensus, Confusion and Controversy. Selected Land Reform Issues in SubSaharan Africa, Washington DC: World Bank COHRE (2006) Listening to the Poor: Housing Rights in Nairobi, Kenya, Geneva: Gentre on Housing Rights and Evictions

Economist (2008) 'Legal Titles for the Poor', 5 June

Fukuda-Parr, Sakiko (2008) Are The MDGs Priority in Development Strategies and Aid Programmes? Only Few Are!, International Poverty Centre Working Paper 48, Brasilia

Fukuda-Parr, S.; Lawson-Remer, T. and Randolph, S. (2008) Measuring the Progressive Realization of Human Rights Obligations, Economic Rights Working Paper Series, University of Connecticut, Storrs

Gassmann, Franziska and Behrendt, Clarissa (2006) Cash Benefits in Low-income Countries: 
Simulating the Effects on Poverty Reduction for Senegal and Tanzania, Issues in Social Protection, Discussion Paper 15, Geneva: Social Security Department, International Labour Organization

Government of Indonesia (2007) Let's Speak Out for the MDGS: Achieving the Millennium Development Goals in Indonesia, Jakarta: Government of Indonesia and United Nations Development Programme

Government of Kenya (2005) MDG Status Report for Kenya, Nairobi: UNDP, Government of Kenya and Government of Finland

Government of Vietnam (2005) Vietnam Achieving the Millennium Development Goals, Fourth MDG Report, Hanoi: Government of Vietnam

Huchzermeyer, Marie (2008) 'Slums Law Based on Flawed Interpretation of UN Goals', Business Day, 19 May

Jahan, Selim (2003) 'Millennium Development Goals and Human Rights', in Human Rights in Developing Countries: How can Development Cooperation Contribute to Furthering their Advancement, Berlin: InWent

Langford, Malcolm (ed.) (2008) Social Rights Jurisprudence: Emerging Trends in International and Comparative Law, New York: Cambridge University Press

Langford, Malcolm (2007) 'Beyond Formalisation: The Role of Givil Society in Reclaiming the Legal Empowerment Agenda', Norwegian Ministry of Foreign Affairs, Legal Empowerment - A Way Out Of Poverty 4: 41-66

Mizunoya, S.; Behrendt, C.; Pal, K. and Léger, F. (2006) Can Low Income Countries Afford Basic Social Protection? First Results of a Modelling Exercise for Five Asian Countries, Issues in Social Protection Discussion Paper 17, Geneva: Social Security Department, International Labour Organization

Nelson, P. (2007) 'Human Rights, the Millennium Development Goals, and the Future of Development Cooperation', World Development 35.12: 2041-55

Pogge, Thomas (2005), 'The First UN Millennium Development Goal: A Cause for
Celebration?', in A. Føllesdal and T. Pogge (eds), Real World Justice: Grounds, Principles, Human Rights, and Social Institutions, Berlin: Springer: 317-38

Saith, A. (2006), 'From Universal Values to Millennium Development Goals: Lost in Translation', Development and Change 37.6: 1167-99

Seymour, Dan and Pincus, Jonathan (2008) 'Human Rights and Economics: The Conceptual Basis for their Complementarity', Development Policy Review 26.4: 387

Smith, Stephen (2007) 'The Millennium Development Goals and the Struggle Against Poverty Traps', presentation at the United Nations Economic and Social Council meeting on 'Eradicating Poverty and Hunger - Joining Forces to Make it Happen', 2 April

UN GESCR (1991) General Comment No. 3, The Nature of States Parties' Obligations (Fifth Session 1990), UN Doc. E/1991/23, annex III at 86, UN Committee on Economic, Social and Cultural Rights

UN Commission on Human Rights (1993) Resolution 1993/77 on Forced Evictions, Geneva

UNDP (2008) Human Rights and the Millennium Development Goals Making the Link, Oslo: United Nations Development Programme Oslo Governance Centre

UNIFEM (2004) Pathway to Gender Equality: CEDAW, Beijing and the MDGs, New York: United Nations Development Fund for Women

UN-Habitat (2007) Forced Evictions - Towards Solutions? Second Report of the Advisory Group on Forced Evictions to the Executive Director, Nairobi: UN-Habitat

UN OHCHR (2008) Claiming the MDGs: A Human Rights Approach, Geneva: Office of the United Nations High Commissioner for Human Rights

UN OHCHR, UNICEF and NCHR (2008) Human Rights and MDGs in Practice: A Review of Country Strategies and Reporting, Geneva: Office of the United Nations High Commissioner for Human Rights 